\title{
APPENDICULAR ABSCESS TRACKING INTO SCROTUM THROUGH THE PATENT PROCESSUS VAGINALIS IN AN ADULT
}

Shashidhara $\mathrm{P}^{1}$, Puneetha $\mathrm{K}^{2}$, Seshasayi $\mathrm{M}^{3}$

\section{HOW TO CITE THIS ARTICLE:}

Shashidhara P, Puneetha K, Seshasayi M. "Appendicular Abscess Tracking into Scrotum through the Patent Processus Vaginalis in an Adult". Journal of Evolution of Medical and Dental Sciences 2014; Vol. 3, Issue 46, September 22; Page: 11314-11317, DOI: $10.14260 /$ jemds/2014/3478

ABSTRACT: Urgent surgical exploration of the scrotum of a child or teenager who presents with a painful and swollen scrotum is paramount if testicular torsion should not to be missed. It is extremely rare for a non-scrotal pathology to present with acute scrotal signs. Here we present such a rare case in an adult and emphasize the importance of being aware of this potential clinical pitfall. Abscess formation is a well-known complication of appendicular pathology and it may be intra-abdominal or pelvic. Acute scrotum following an appendicular abscess perforation is very rare.

KEYWORDS: Appendicitis; perforated appendix; acute scrotum; patent processus vaginalis.

INTRODUCTION: PRESENTATION: We report a case of an adult male aged 30 years who presented to casualty with 2-3 episodes of vomiting and severe excruciating pain in the scrotum which aggravated on elevation. A clinical diagnosis of Acute Scrotum was thought of. Patient was febrile and had a tender, red, and swollen right hemiscrotum.

The right testicle appeared elevated. He was mildly tender in his central abdomen with minimal tenderness in the lower abdomen. No localizing abdominal signs were noted. He had an increased white cell count $13,000 / \mathrm{mm}^{3}$ and USG of scrotum showed both testes normal in echogenecity and vascularity. The sonologist found oedematous cord and contents with minimal collection on the right side tunica vaginalis testis.

PROCEDURE: The patient was taken up for emergency right hemiscrotal exploration and on incising the skin and dartos, tunica vaginalis was found to contain yellow pus-like material (Fig. 1), testis was found to be congested but normal in size and consistency. The sac was traced upwards, found to enter the inguinal canal which was opened and traced up to internal ring. As the sac in the cord was opened thick pus poured out (Fig. 2). Since pus was tracking from abdominal cavity; abdomen was opened with a right lower para-median incision as shown in the picture below.

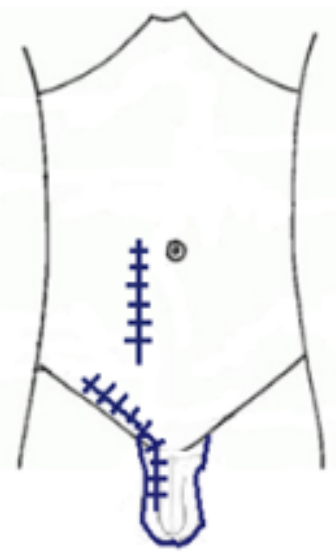


Greater Omentum was found occupying the right iliac fossa with pus, on further dissection, a Perforated Appendix was found adherent near the internal inguinal ring (fig-3). Pus had tracked down into scrotum along the patent Process us Vaginalis. Appendectomy was performed and specimen was sent for histopathological examination, and both the abdomen and scrotum washed copiously with saline before closure. Pus from both scrotum and around apppendix was sent for culture and sensitivity the patient was on broad spectrum antibiotics for 5 days and made an uneventful recovery.

DISCUSSION: The process us vaginalis is a developmental out pouching of the peritoneum that is present from around week 12 of gestation. In boys, it proceeds with testis in its descent from the abdominal to the scrotal position and usually closes during the period from a few weeks before to a few weeks after birth. The portion around the testis remains as the tunica vaginalis.

The process us vaginalis has been found to be patent in $80 \%$ to $95 \%$ of male newborns, the incidence then decreasing to $60 \%$ at one year, $40 \%$ at two years, and $15 \%$ to $37 \%$ thereafter.[1,2] $\mathrm{A}$ patent process us vaginalis can present as a hydroceleor congenital inguinal hernia. Scrotal abscess as a complication of acute appendicitis is a very rare clinical entity. The condition occurs when pus from supportive appendicitis tracks down through a patent process us vaginalis into the scrotum. (Fig. 1)

To date, very few cases have been described in the literature. Scrotal abscess as a complication of appendectomy has been mentioned only very infrequently. A Medline search produced fewer than 20 reported cases.[1,3,7] A scrotal abscess occurring without a history of appendectomy, as happened in our patient, which is even less common. A Medline search produced fewer than five such case reports. ${ }^{[8,10]}$

The presentation of an acutely tender, red and swollen hemiscrotum inevitably raises the suspicion of testicular torsion. Surgical exploration in these cases should be done without delay if the correct diagnosis is to be corroborated and the viability of the test is ensured. Other possible causes of an acute scrotum include torsion of a testicular appendage, epididymoorchitis, and incarcerated hernia.

As an intra-abdominal cause for acute scrotal signs is an extremely unusual clinical scenario, a good deal of discernment and lateral thinking is required to diagnose and manage the patient properly, as it can be tempting to explore the scrotum alone without looking upwards. Ultrasound imaging of the abdomen and scrotum can help in the diagnosis [10] but there is no substitute for a high index of suspicion.

CONCLUSION: Acute appendicitis presenting with scrotal signs due to a patent processus vaginalis is an extremely rare clinical entity. To date, few cases have been reported in the medical literature. The possibility of an intra-abdominal abscess leading to the presentation of an acute scrotum secondary to a patent process susvaginalis should always be kept in mind. Thorough scrotal and abdominal lavage and removal of the source of sepsis are keys to successful management.

\section{REFERENCES:}

1. Rahman N, Lakhoo K: Patent processusvaginalis: a window to the abdomen. Afr J Paediatr Surg 2009, 6: 116-117. 
2. Watson DS, Sharp KW, Vasquez JM, and Richards WO: Incidence of inguinal hernia diagnosed during laparoscopy. South Med J 1994, 87: 23-25.

3. Saleem MM: Scrotal abscess as a complication of perforated appendicitis: a case report and review of the literature. Cases J 2008, 1: 165.

4. Bingol - Kologlu M, Fedakar M, Yagmurlu A, Dindar H, Gokçora IH: Anexceptional complication following appendectomy: acute inguinal and scrotal suppuration. Int Urol Nephrol 2006, 38: 663-665.

5. $\mathrm{Ng} \mathrm{KH}$, Chung YF, Cwilde C, Chee C: An unusual presentation of acute scrotum after appendicitis. Singapore Med J 2002, 43: 365-366.

6. Thakur A, Buchmiller T, Hiyama D, Shaw A, Atkinson J: Scrotal abscess following appendectomy. Pediatr Surg Int 2001, 17: 569-571.

7. Gan BS, Sweeney JP: An unusual complication of appendectomy. J Pediatr Surg 1994, 29: 1622.

8. Yasumoto R, Kawano M, Kawanishi H, Shindow K, Hiura A, Kim E, Ikehara T: Left acute scrotum associated with appendicitis. Int J Urol 1998, 5: 108-110.

9. Iuchtman M, Kirshon M, Feldman M: Neonatal pyoscrotum and perforated appendicitis. J Perinatol 1999, 19: 536-537.

10. Satchithananda K, Beese RC, Sidhu PS: Acute appendicitis presenting with a testicular mass: ultrasound appearances. Br J Radiol 2000, 73: 780-782.

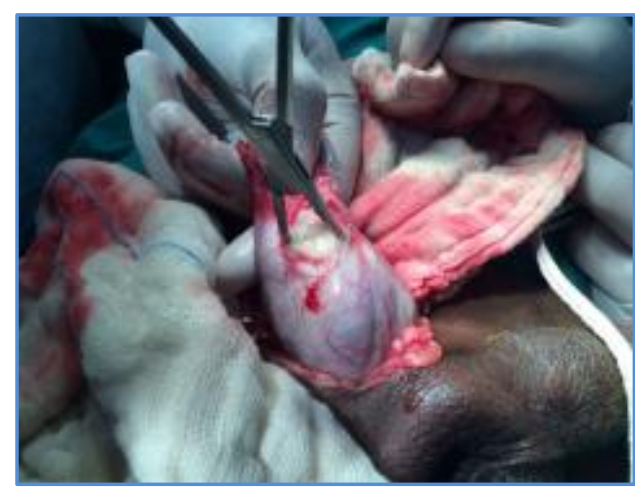

Fig. 1: coverings of testis opened, revealing pus

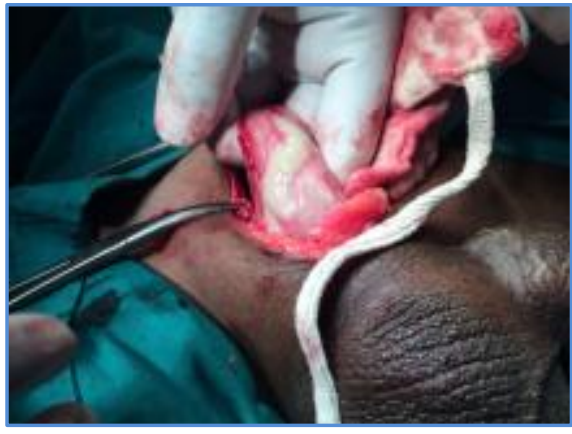

Fig. 2: spermatic cord dissection showing pus

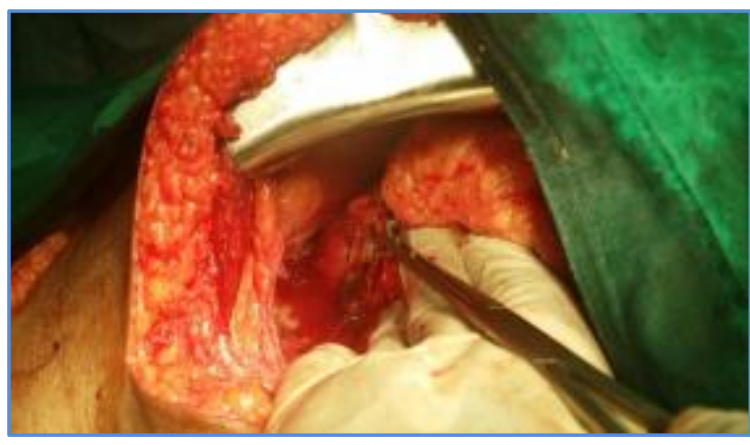

Fig. 3: perforated appendix near internal ring with gangrene 


\section{CASE REPORT}

\section{AUTHORS:}

1. Shashidhara P.

2. Puneetha K.

3. Seshasayi M.

\section{PARTICULARS OF CONTRIBUTORS:}

1. Assistant Professor, Department of Surgery, Sree Raja Rajeshwari Medical College Hospital, Bangalore.

2. Post Graduate, Department of Surgery, Sree Raja Rajeshwari Medical College Hospital, Bangalore.

3. Professor, Department of Surgery, Sree Raja Rajeshwari Medical College Hospital, Bangalore.

\section{NAME ADDRESS EMAIL ID OF THE} CORRESPONDING AUTHOR:

Dr. Shashidhara $\mathrm{P}$, $33 / 1,1^{\text {st }}$ 'B' Cross, $5^{\text {th }}$ Block,

Banashankari $3^{\text {rd }}$ Stage, Bangalore-560085.

Email:dr.shashi@gmail.com

Date of Submission: 08/09/2014. Date of Peer Review: 09/09/2014. Date of Acceptance: 15/09/2014. Date of Publishing: 22/09/2014. 